\title{
The Advantages and Disadvantages and Multi-Dimensional Development of Online Education in the Post-Epidemic Era
}

\author{
Yiming Tian ${ }^{1, *,}$, Yanmin $\mathrm{Wu}^{2, *, \dagger}$ \\ ${ }^{1}$ School of English Studies, Tianjin Foreign Studies University, Tianjin, China \\ ${ }^{2}$ College of Arts \& Science, New York University, New York, United States \\ *Corresponding author.Email: ${ }^{*} 3101500548 @ q q . c o m,{ }^{2} y w 3171 @ n y u . e d u$ \\ Those authors contributed equally.
}

\begin{abstract}
The coronavirus pandemic since 2019 has forced students and educators across all levels of education to rapidly adapt to online learning. Fast adapting to the new teaching and learning challenges, many online education platforms, such as Zoom, Microsoft Teams, and Nearpod, emerged amidst the pandemic to tackle students' learning dilemma. Even though these emerging technology-integrated platforms do convince student and teaching in the virtual space, there are many challenges existing such as technology enhancement and mastry, challenging pedagogical skills, and student engagement. Thus, this paper aims to review (1) the features and advantages of online classes; (2) the challenges and possible solutions of online classes; and (3) unique opportunities afforded by the online classes. The purpose of this paper is to shed lights on future online education development in regard to how to better serve the needs of teachers and students.
\end{abstract}

Keywords: Education, Online classes, Technology, Poor Alleviation.

\section{INTRODUCTION}

The coronavirus pandemic since 2019 has forced students and educators across all levels of education to rapidly adapt to online learning. Similarly, amidst the coronavirus pandemic, the Chinese government issued a "Double Reduction" policy, a policy to call for schools on reducing out-of-school training on various academic subjects for students for the purpose of reducing students' burden. This policy also emphasized the needs to establish more optimal online learning services project to make full use of information technology to improve the overall education environment.

Despite urgency and necessity of online education in creating convenience and binding people together regardless of geographic boundaries, it also comes with its disadvantages. Students are less likely to concentrate as much as compared to studying in physical classroom due to a variety of reasons (e.g., learning environment outside traditional classrooms could be full of distractions; there is no direct contact from instructors to discipline students to concentrate;). Fast adapting to the new teaching and learning challenges, many online education platforms, such as Zoom, Google Meet, and Skype, emerged amidst the pandemic to tackle students' learning dilemma. Even though these emerging technology-integrated platforms do convince students and teaching in the virtual space, there are many challenges existing such as technology enhancement and mastery, challenging pedagogical skills, and student engagement. Thus, this paper aims to review (1) the features and advantages of online classes; (2) the challenges and possible solutions of online classes; and (3) unique opportunities afforded by the online classes. The purpose of this paper is to shed lights on future online education development in regard to how to better serve the needs of teachers and students.

\section{FEATURES AND ADVANTAGES OF ONLINE CLASSES}

The form of online classes existed long before the abruption of online education forced by the sudden outbreak of the coronavirus. Before this new abruption of online education, online classes have always served as supplementary to in-person education that happens in 
a physical space. However, the coronavirus pandemic has forced education at all levels to shut down and turn completely online for a long period of time. Not only international students who were unable to attend classes due to the shutdown of the border, domestic students were also unable to attend classes due to the lockdown of the city and the campuses. The data in statistic suggests that in 2019, $17.6 \%$ of higher education students in the United States were taking exclusively distance learning courses [1]. A further $19.7 \%$ of students were taking at least some distance learning courses [1]. Thus, a total of more than one third students in United States have already had some experiences in online classes before the pandemic. The recent pandemic drove the data to a peak. Now, due to the global pandemic, online classes have become a new normal for teachers and students globally. Online delivery of classes becomes mandatory for schools globally for health purposes.

The integration of technology into education is not just an alternative form of teaching and learning but also a form toward educational innovation. The published research has indicated the features and advantages of online classes that could benefited both teachers and students.

\subsection{Basic Features for Online Learning}

There are several applications/platforms that schools globally widely use/subscribe for their online classes, which include but not limit to Zoom, Virtual Classroom, BrianCert, Google Classroom, etc. Zoom is one of the most popular platforms used in United States. The general features shared by those above-mentioned platforms/applications include but not limit to video chatting, breakout rooms, chatting boxes, file uploading, reaction buttons, screen-sharing, etc. Such features shared by these platforms/applications are usually intended to create an online space that include as many functions as in a physical classroom (e.g., They are able to form small discussion groups; students are able to virtually raise up hands, and they can choose send private messages to certain people in class through chat box) but also include other features that a physical classroom cannot provide (e.g., Learners are able to watch the lecture video repeatedly).

\subsection{Video/Audio Recordings}

Besides all the similar features provided to create a traditional in-person classes like virtual classroom, one big feature that online classes offered that a traditional in-person classes cannot offer is video/audio recordings. With this feature, teachers are allowed to record all class sessions, save the recordings, and upload the recordings to the cloud or other services so students will be able to re-watch and review the class sessions along with class contents whenever they would like to. This feature provides opportunities for students to review the class at their convince, specifically for the ones who are unable to attend the class. Even though they lose the interaction during the actual class sessions, at least they are able to catch up with as much content as they can with the recordings, which is a feature that attending physical classes cannot do.

\subsection{Breakout Rooms}

Another popular feature that many online learning platforms provide is breakout rooms. Most of those online learning platforms have the breakout room feature that allows teachers to randomly or manually assign students to different break out rooms for discussion. Such feature was originally designed to imitate the traditional in-person classrooms that students can have peer discussion whenever needed because it would be inconvenient and inefficient for students to find the peers and form the group in the virtual space. However, the breakout room feature actually exceeds what was intended. With the breakout room feature, teachers can randomly assign students to different breakout rooms for peer discussion. Traditionally, students in in-person classes usually have settled seats or they usually would like to sit around friends that they are familiar with, thus the peer discussion groups are often bounded by the physical space. Many of them would simply pick the peers they are familiar with or the peers sit close to them for discussion. The randomized system of the breakout room feature can help students to step out of the comfort zone and get to know more peers in class, instead of just the peers they are familiar with or the peers sit around them, which is extremely helpful in terms of getting diverse perceptions of topics discussed in class.

\section{4. "Location"}

The form of online classes frees the physical space of classroom, and the general learning environment is not as formal as that of on campus classes. Students and teachers can conduct lectures in any place as long as they have appropriate technological and network support. Students are able to choose space that they are comfortable with no restrictions. The breakdown of geographic constraint is one of the most innovative features of the online platform. It suggests that learning can happen not only in three dimensional classrooms, but it also be generated online while the learner is sitting in his/her own bedroom, coffee shop or anywhere they find appropriate. The freedom of space saves both instructors and learners time and cost on traveling and dorm room expenses, and most importantly, it calls for an idea that learning can be a causal and comfortable process: it does not have to be done in a formal and serious way which there is requirement for seating, 
dress code and certain behavioral constraint such as eating, because all attendees are less likely to affect each other when classes are conducted online, for example, the chewing sound of a student won't disrupt others' concentration as long as they are muted.

\section{CHALLENGES AND POSSIBLE SOLUTIONS OF ONLINE CLASSES}

Despite the fact that it has many beneficial features, many challenges of online education are noticed. As the tuition stay the same, students and parents often expect same or even better learning experience and learning outcome online, but there are things that a person can do but computers are unable to achieve.

\subsection{Need for Technical Enhancement and Mastery of Technology}

Technology issues often happen during online classes such as disconnection and lagging. However, disconnections and lagging can never be a problem for in-person classes. During in-person classes, students and teachers will never need to spend time figuring out a variety of functions available in order to submit homework or to speak up in classes. Such incidents happen frequently during online classes. The functioning of online courses fully depends on technologies, which requires teachers and students to master the functions of different online platforms. Also, stable and fast internet is also a key to an uninterrupted lecture. Many schools transit well into the form of online lecturing, while some have a relatively rough path with weaker infrastructure. Study suggests that online class requires greater bandwidth. Video streaming, graphics and large amount of students attending class will easily cause internet lagging and disconnection [2]. Schroeder also mentioned that it would be a disaster for both students and teachers if the system crash and data was lost during some important lecture or even during final period. Thus, the school would need a stronger IT team to constantly check for the functioning of software and hardware to make sure the service is reliable.

The mastery of technology, specifically for older generations, is also an issue needed to be attended. Younger generation usually don't have too many issues mastering the use of technology. However, even younger generation needs to take the time to familiarize themselves with the platforms, in addition to the fact that it is usually the case different courses/instructors would prefer to use different platforms. It is often the case that the first few classes are usually in chaos because people are familiarizing themselves with the many functions available. Also, switching platforms in-between courses would also create chaos.
Some senior professors who are used to deliver lectures in person with whiteboards and markers also struggle with adaption of technologies. The situation regarding to the adaption of technology would certainly get better with time, but for now it's essential for schools to establish systematic training of technology used so neither teachers' nor students' time would be wasted due to technology issues once the class begin.

\subsection{Edtech Integration means higher standard for traditional teachers}

The deeper educational technology integration oftentimes places a higher standard for traditional teachers. As the online classes are fully integrated with technology, the course design should also adapt to the new changes and be different from conventional in-person lectures. It's important to facilitate active learning in classes regardless of what forms the classes are. According to Mitchell and Nicole, "Active learning is...having students engage in some activity that forces them to think about and comment on the information presented." [3], and research indicates that examination score improves by $6 \%$ with active learning sessions. As active learning activities are already not easy to generate in face-to-face classrooms, having to do it online makes the process even more challenging for teachers. The three major components of active learning includes: developing and maintaining social connections, interacting with lecture content and interacting with both people and contents [4]. Forms of interactions in online classes should also be reformed in order to achieve or exceed the in-person class results.

First, the interaction with people through online platforms will not be as genuine or authentic as directly face to face. In in-person classes, teachers are able to capture students' emotions and reactions directly through their facial expressions, body languages, whispers and many other flexible ways; but the ways for teachers and students to interact is rather stilted. Professor Mitchell suggests using annotate tools for students to express feelings, but it is nothing comparing to direct communication. Emojis are not as vivid and the communication wouldn't be as efficient and accurate. Also, a lot of comments and reactions happened during class is not deliberate, and some introvert students would be too self-conscious to send anything on the platform because others and teachers will all be able to see that the messages are from them. The online classes would make the group of students be too passive to engage in active learning.

Second, teachers need to redesign the courses in order for students to actively learn through the online platform. Many activities cannot function as well if people aren't physically in a same place. There are many interactive online activities there for teachers to use such as Kahoot, and teachers can try make up 
activities on their own. However, the variables that teacher cannot control is a lot more than that of in-person class. If some kids are distracted or they lose internet connections, it will be hard for the whole group to actively engage in the activity. For example, for paired up teams, if one lost interest and got distracted, unlike how it's during in-person classes that teachers could remind them in time, there isn't many things that a teacher can do at the point. It's more challenging for teachers to make regulate the class through online platform. Severe grading system could be a solution, but when the whole learning environment becomes too tense it also put students under too much pressure.

\subsection{Student engagement}

The sense of isolation affects learners' participation in online class. Vonderwell reported that online learning participants indicated a lack of connection with the instructor, especially "one-on-one" relationship with the instructor. Vonderwell revealed that one participant stated, "I still feel like I know a little bit about my instructor, but not the same way that I would if I was in a class. I don't know much about her personality at all" [5]. Some learners do not actively participate in learning but keep silence as the teacher instruct the class, with little opportunity for interaction or engagement with the teacher. Woods in his study on the online communication between instructor and learner reported that online learners reported feeling isolated from faculty as well as other learners in the online courses they had taken [6].

It is very easy for a learner to distract himself or herself from the material and thus without active participation in online classes. It is challenging for a teacher to adapt their content and approach as needed. This is even more pronounced issues in the online class such as learners may have potentially pulled out their phones, be distracted by others in their environment, or simply got up and moved away from their device. A more active approach to education in the digital environment can help improve engagement, mobilization, and retention of knowledge.

In response to these issues mentioned above, Donna Smith and Katy Smith [7] noted that there are three cases for passive learners, with regard to the learners themselves, their tutors and institutions:

Learners 'passively engaging' can safely find out information, without the risks associated with being an active forum user (i.e., fantasy and dominance)

It is a more 'gentle' approach than active forum use for students; they may 'passively' engage at first, but as they become enculturated chose to 'actively engage'
By accepting 'passive engagement' as a learning strategy, institutions give control to learners and respect their decisions [7].

In online distance education, delayed feedback from instructor might be also a source of challenge for learners. When students have questions related to the course, they usually need someone more experienced or knowledgeable, such as peers or instructors to help them. The person that came to their mind first was the instructor. Thus, when the support from the instructor was not available, negative experiences will often be brought up when students expect timely feedback from instructors on group discussion, exams or tests, and submitted work but cannot get them in time. When students were not provided with feedback from the instructor in time, they would be likely to felt frustrated, depressed and less motivated in learning.

\section{USE OF ONLINE CLASSES AS SOCIETAL RESOURCES}

Transformation to online classes is not only a change of classroom media. It can make series of social changes since it breaks down physical walls that used to limit people and the extension of education in some remote areas.

Online education is well adapted to the needs of different socio-economic groups in developing countries. New technologies, the Internet, streaming video, net-meeting etc. now makes higher education more accessible and affordable for many students, specifically for those who have been unable to pursue higher education in a traditional in-class setting [8]. In an online environment, students are not required to physically attend university; the university comes to them. Students thus save on time and travel costs. Also, the cost of online education is a fraction of traditional 'brick-and-mortar' education. A curriculum, once created, can be offered electronically, not just to hundreds of locally-based students, but to tens of thousands around the world [9].

Many of the difficulties and concerns experienced by women, particularly those in rural or low-income areas, point to the fact that distance education may be an ideal way for them to access education, since it potentially enables them to do most of their studying from home if they are willing to do so, thus reducing the possibility for them to conflict with their other social or cultural requirements [10]. Also, many parents in low-income areas often have to face with a tough decision of which child to send to school and which not because of they usually cannot afford all the expenses that comes along with schooling. However, online classes can efficiently reduce overall cost of education. Online classes don't require physical buildings so the cost for schools itself would be lower, which could help reducing the tuition. 
Also, the students do not need to travel or pay for dorms. As online classes become a major trend, the courses should be more diverse in the near future. It doesn't necessarily always have to be live streaming. Teachers could also prerecord lectures for students to self-study for more technical classes which requires less interaction. Such classes could further lift burden of financially troubled families because they only need to pay for one package then all of their kids are able to have access to it.

However, despite the potential of online education as a way for poor alleviation in education, there are many challenges. For example, enrolling in online classes required students in remote areas to have devices that equipped with internet access. Learning online also have demands on the device's storages and the internet bandwidth. No matter which on, internet access, storage, or internet bandwidth, adds to the family's overall educational costs. Internet access and internet bandwidth also place demands on the local infrastructure.

\section{CONCLUSION}

The fast advancement of technology as well as the global pandemic have brought online education to the forefront of education. Online education has existed long before the spread of the global pandemic, but it has always played a supplemental role for in-person, face-to-face education. When the natural disaster has forced us to all study from home on a computer, it is necessary to rethink the role of online education and the benefits and challenges it unfolds.

\section{REFERENCES}

[1] Published by Erin Duffin, \& 5, M. (2021, May 5). U.S. student distance LEARNING enrollment 2019. Statista.

https:/www.statista.com/statistics/944245/studentdistance-learning-enrollment-usa/.

[2] Schroeder, R. (2001, January 1).Institutional Support Infrastructure for online classes. Metropolitan Universities. Retrieved October 16, 2021, from https://journals.iupui.edu/index.php/muj/article/vie w/19880.

[3] Mitchell, Nicole. "Active Learning in Online Classes."

[4] Schoology. (n.d.). The TPACK framework explained (With Classroom Examples). Schoology.

[5] Vonderwell, S. (2003). An examination of asynchronous communication experiences and perspectives of students in an online course: A case study. Internet and Higher Education, 6(1), 77-90.
[6] Woods, R.H. (2002). How much communication is enough in online course? Exploring the relationship between frequency of instructor-initiated personal email and learners' perceptions of and participation in online learning. International Journal of Instructional Media, 29(4), 377-394.

[7] Donna Smith; Katy Smith (2014). Case for 'Passive' Learning - the 'Silent' Community of Online Learners. In European Journal of Open, Distance and e-Learning - Vol. 17 / No. 2

[8] Biance M. B. and Carr-Chellman, A. A. (2002). Exploring Qualitative Methodologies In Online Learning Envrionments. The Quarterly Review of Distance Education, 3(3), 251-260.

[9] Habibullah Khan; Jeremy B. Williams (2006) Poverty Alleviation through Access to Education: Can E-Learning Deliver?

[10] Kanwar, A. S and Taplin, M (2001) (eds) Brave New Women of Asia: How Distance Education Changed their Lives. Vancouver, British Columbia: The Commonwealth of Learning. 